\title{
The Orient of Style
}





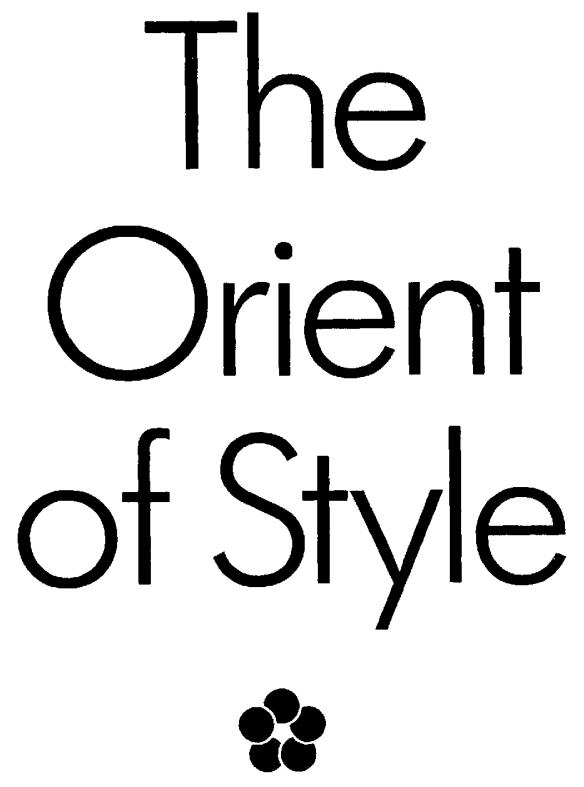

Modernist Allegories of Conversion

BERYL SCHLOSSMAN

Duke University Press

Durham and London 1991 
(C) I99I Duke University Press

All rights reserved

Printed in the United States of America

on acid-free paper $\infty$

Library of Congress Cataloging-in-Publication Data appear on the last page of this book. 